Original Research Article

\title{
A pharmacovigilance study of antiretroviral therapy in HIV positive out patients at a tertiary care teaching hospital
}

\author{
Muneeshwar Reddy T. ${ }^{1}$, Durga Prasad T. S. ${ }^{2}$, Sravani Gundramy Reddy ${ }^{2 *}$, Sravani Dudu ${ }^{2}$, \\ Rameela Mohan², Kali Prasanna Punnamaraju², Seetharam Babu Dudekula ${ }^{2}$
}

\begin{abstract}
${ }^{1}$ Department of General Medicine, ART Centre, SV Medical College, Tirupati, India ${ }^{2}$ Department of Pharmacy Practice, Sri Padmavathi School of Pharmacy, Tiruchanoor, Tirupati, India
\end{abstract}

Received: 03 October 2018

Revised: 27 October 2018 Accepted: 01 November 2018

*Correspondence to:

Dr. Sravani Gundramy Reddy, Email: gsravanipharmd@ gmail.com

Copyright: (C) the author(s), publisher and licensee Medip Academy. This is an openaccess article distributed under the terms of the Creative Commons Attribution NonCommercial License, which permits unrestricted noncommercial use, distribution, and reproduction in any medium, provided the original work is properly cited.

\begin{abstract}
Background: Anti-Retroviral Therapy regimen (ART) is the only treatment option for treating the HIV positive patients for improving the immune system by increasing the CD4 cells. But eventually these medications lead to development of some Adverse Drug Reactions (ADRs) in seropositive patients under treatment.

Methods: A prospective observational study was conducted for 6 months from March to August 2018 at ART Centre, Sri Venkateswara Ramnarayan Ruya Government General Hospital (SVRRGGH), Tirupati.

Results: Out of 216 ADRs identified, majority where identified in females $(54.35 \%)$. Most common regimen caused ADR was tenofovir+ lamivudine+ efavirenz (TLE) (55.55\%). Data were analysed using the chi-square test were Pvalue was found to be 0.0024 . Majority of ADRs were found in patients of age group between 31-35years was found to be 45 (20.83\%) followed by age group between 41-45years was found to be 40 (18.51\%). Most of the ADRs were related to central nervous system $(27.31 \%)$ followed by metabolic disorders $(26.38 \%)$, hematologic system (23.14\%), gastrointestinal system (12.96\%), dermatologic system $(9.25 \%)$, renal system $(0.46 \%)$ and musculoskeletal system $(0.46 \%)$. On evaluation of WHO-UMC causality of ADRs, majority were found to be possible (78.7\%). The Hartwig and Siegel's severity assessment scale showed that most of the ADRs were mild (64.42\%). The Schumock and Thornton preventability scale showed that $50.92 \%$ patients ADRs were probably preventable.

Conclusions: As most of the ADRs were observed in patients receiving TLE regimen. So, patients receiving TLE regimen need intensive monitoring. Doctors, nurses, pharmacist must focus on early detection and prevention of ADRs, based on their severity.
\end{abstract}

Keywords: Adverse drug reactions, Modified Hartwig, Siegel's severity assessment scale, TLE regimen, WHO-UMC causality scale

\section{INTRODUCTION}

HIV (Human Immunodeficiency Virus), a virus that is being transmitted through sex between men and women, injections, mother to child, sex workers and men who have sex with men via sexual fluids, blood and breast milk. ${ }^{1}$ ART (Anti-Retroviral Treatment) among HIV patients has changed HIV from life threatening to chronic condition. ${ }^{2}$ According to global HIV and AIDS statistics, 36.9 million people globally were living with HIV in 2017, among them 21.7 million people were accessing antiretroviral therapy. ${ }^{3}$

HAART (Highly Active Anti-Retroviral Therapy) was introduced in 1996 with three antiretroviral drugs with the combination of two nucleoside reverse transcriptase inhibitors (NRTIs) and one protease inhibitors (PI), that lead to reduction of mortality and morbidity related to AIDS. ${ }^{4}$ Yet, the management of HIV is increasingly complex, due to ADRs, risk of drug resistance which leads 
to decrease the quality of life in some patients. Doctors, Pharmacists and Nurses have the responsibility of closely monitoring for ADRs. So that adherence to the prescribed treatment is ensured. ${ }^{5}$

ADRs may be common or specific to class of drugs. Drugs classified as Non-Nucleoside reverse transcriptase inhibitors (NNRTIS) which include efavirenz (EFZ) and nevirapine (NVP) cause hypersensitivity rash, hepatotoxicity and Neurotoxicity. Nucleoside Reverse Transcriptase Inhibitors include zidovudine (AZT), lamivudine (3TC), stavudine (d4T) cause Anemia, Nausea, Rashes, Peripheral neuropathy, Lipodystrophy and lactic acidosis. Protease inhibitors include ritonavir, indinavir cause hyperlipidaemia, lipodystrophy, hyperglycaemia. $^{2}$

ADRs documented may be mild to severe and short to long term. It may differ among developed and developing countries because of some conditions such as malnutrition, opportunistic infections. Risk factors such as patient age, gender, duration on treatment, CD4 count and viral load may also play a key role in developing ADR. ${ }^{2}$

Knowledge regarding the treatment adherence during follow-up visits results in increasing the effectiveness by reducing the viral suppression in patients receiving ART regimen. ${ }^{1}$ Most of the adverse drug reactions remain unnoticed or not reported by the patients. Thus, continuous evaluation will be benefit of the ART that helps in achieving ultimate goal of making the treatment safer and more effective to the patients. ${ }^{6}$

This study was conducted to monitor, detect, assess, and understand the severity pattern checking the preventability of ADRs in HIV positive patients receiving ART therapy.

\section{METHODS}

This is a Prospective observational study conducted at the ART center, Sri Venkateswara Ramnarayan Ruya Government General Hospital (SVRRGGH), Tirupati, India for about 6 months from March- August 2018. In this duration the observed patient prescription/study population was 1020 .

\section{Inclusion criteria}

All patients above 16 years of age receiving ART of either sex were included.

\section{Exclusion criteria}

- Patients receiving anti-tubercular treatment

- Opportunistic infections

- Pregnant women.

Demographic details, CD4 count, weight, Haemoglobin, available laboratory data, drugs used, ADRs observed were entered in a specially designed data collection form.

\section{Regimens used in patients receiving ART therapy}

- Zidovudine + Lamivudine + Nevirapine. (ZLN)

- Tenofovir + Lamivudine + Efavrirenz. (TLE)

- Lopinavir + Ritonavir, Tenofovir + Lamivudine. (LR, TL).

\section{Assessment of observed ADR by using following scales}

- WHO-UMC causality assessment scale.

- Modified Hartwig and Siegel's severity assessment scale.

- Modified Schumock and Thornton preventability scale.

This study was approved by Institutional ethical committee of S.V. Medical College, Tirupati (LR, TL.No.65/2017). After obtaining approval of ethical committee, Patient's details such as name, age, sex, ART regimens and Adverse Drug Reactions (ADRs) to the antiretroviral drugs data was collected by using CDSCO ADR reporting from.

The collected ADRs was assessed by using WHO-UMC casualty assessment scale whereby they were classified into certain, probable, possible, Severity assessment of ADRs was classified into mild, moderate and severe reactions using modified Hartwig Siegel scale and preventability assessment of ADRs was categorized into preventable or not preventable using the criteria of Schumock and Thornton. Finally, all suspected ADRs were reported to the Adverse Drug Reaction Monitoring Centre (AMC) located in SVMC, Tirupati by using CDSCO Adverse Drug Reaction Reporting Form.

\section{Statistical analysis}

Data were analysed using the chi-square test for estimating the correlation between ADRs and Total number of prescriptions. A $\mathrm{p}$ value of $<0.05$ was considered as statistically significant.

\section{RESULTS}

Present study included 1020 patients those who met the inclusion criteria, a total of 216 ADRs have be observed and reported out of which females were 139 (64.35\%) followed by males $77(35.6 \%)$.

Most of the ADRs were found in patients of age group between 31-35 years was found to be 45 (20.83\%) followed by age group between 41-45years was found to be 40 (18.51\%), age group between 36-40 years was found to be $32(14.81 \%)$, age group between $26-30$ years was found to be $32(14.81 \%)$, age group between $20-25$ years was found to be $27(12.5 \%)$, age group between $46-50$ years was found to be $18(8.33 \%)$, age group between $51-55$ years was found to be $10(4.62 \%)$, age group between 56-60 years was found to be $9(4.96 \%)$ and age group between 61-65 years was found to be $3(1.38 \%)$ (Table 1$)$. 
The TLE regimen used by the patients were found to be $520(50.98 \%)$ followed by ZLN regimen used were 480 $(47.05 \%)$ and LR, TL regimen $20(1.96 \%)$. Among them the highest ADRs are observed in patients using TLE regimen was found to be $120(55.55 \%)$ followed by ZLN regimen $90(41.66 \%)$ and LR, TL regimen $6(2.77 \%)$ (Table 2).

Table 1: Distribution of demographic details.

\begin{tabular}{|ll|}
\hline Characteristics & Number of ADRS (\%) \\
\hline Gender & \\
\hline Female & $139(64.35)$ \\
\hline Male & $77(35.6)$ \\
\hline Age (years) & \\
\hline $20-25$ & $27(12.5)$ \\
\hline $26-30$ & $32(14.81)$ \\
\hline $31-35$ & $45(20.83)$ \\
\hline $36-40$ & $32(14.81)$ \\
\hline $41-45$ & $40(18.51)$ \\
\hline $46-50$ & $18(8.33)$ \\
\hline $51-55$ & $10(4.62)$ \\
\hline $56-60$ & $9(4.16)$ \\
\hline $61-65$ & $3(1.38)$ \\
\hline
\end{tabular}

Table 2: Regimens used.

\begin{tabular}{|c|c|c|c|}
\hline Regimen & $\begin{array}{l}\text { No. of } \\
\text { prescriptions (\%) }\end{array}$ & ADRS (\%) & $\begin{array}{l}\text { P- } \\
\text { value }\end{array}$ \\
\hline TLE & $520(50.98)$ & $120(55.55)$ & \multirow{4}{*}{0.0024} \\
\hline ZLN & $480(47.05)$ & $90(41.66)$ & \\
\hline LR, TL & $20(1.96)$ & $6(2.77)$ & \\
\hline Total & 1020 & 216 & \\
\hline
\end{tabular}

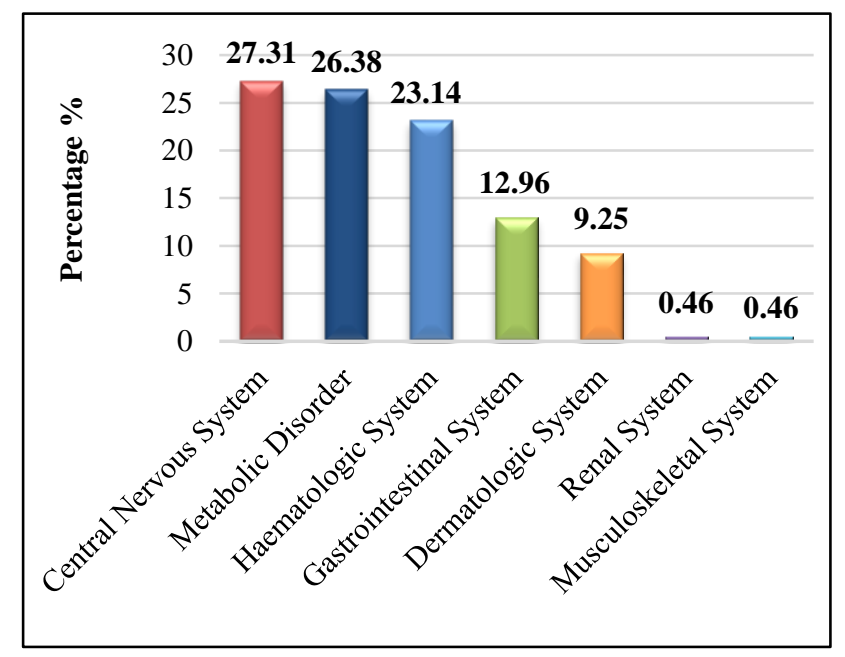

Figure 1: System wise distribution of ADRS.

Out of 216 ADRs, $59(27.31 \%)$ were related to central nervous system (Sleep disturbances, Peripheral Neuropathy, Dizziness), followed by 57 (26.38\%) metabolic disorder (lipodytrophy- lipohypertrophy and lipoatrophy, buffalo hump, horse collar), 50 (23.14\%) hematologic system (anemia), 28 (12.96\%) gastrointestinal system (nausea, vomiting), 20 (9.25\%) dermatologic system (blackish discolouration of nails, tongue), 1 $(0.46 \%)$ renal system (acute kidney injury) and $1(0.46 \%)$ musculoskeletal system (myalgia) (Figure 1).

According to WHO-UMC causality assessment most of the ADRs were categorized as possible 170 (78.7\%) which results that it cannot be either explained by disease or drug followed by Probable 31 (14.35\%) where withdrawal of drug is reasonable and $15(6.94 \%)$ was found to be Certain where re-challenge and withdrawal of drug is done (Table 3).

Table 3: Causality assessment using WHO-UMC scale.

\begin{tabular}{|ll|}
\hline WHO-UMC Scale & ADRS (\%) \\
\hline Certain & $15(6.94)$ \\
\hline Probable & $31(14.35)$ \\
\hline Possible & $170(78.7)$ \\
\hline
\end{tabular}

Severity assessment has been done using modified Hartwig and Siegel's scale where mild (level-1 and level-2) was found to be 137 (64.42\%) which explains ADR is occurred but no change in treatment or withdraw of drug is done followed by moderate (level-3,4) was found to be 58 $(26.85 \%)$ where discontinuation of drug or an antidote is given and severe (level-5,6 and 7) was found to be 21 $(9.72 \%)$ which results in permanent harm/ death to the patient either it may be directly or indirectly (Figure 2).

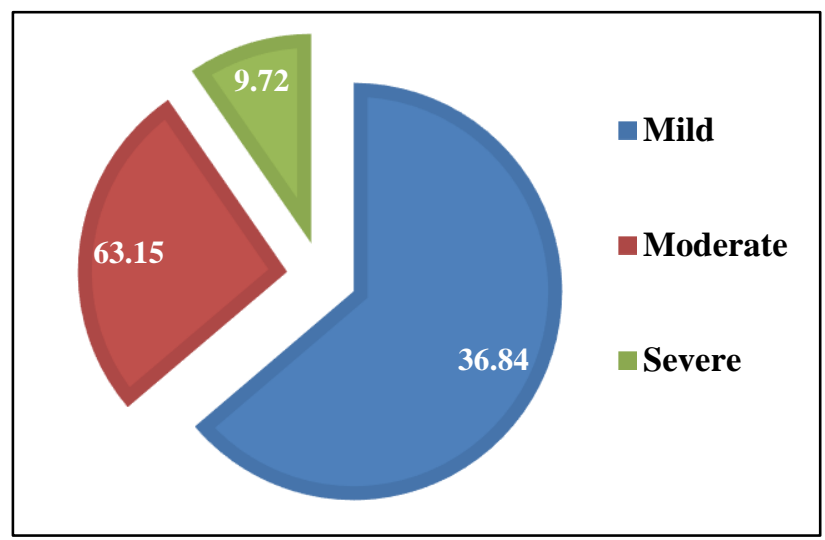

Figure 2: Severity assessment using modified Hartwig and Siegel's scale.

Preventability assessment has been done using Modified Schumock and Thornton scale, where 110 (50.92\%) found to be probably preventable when the ADR is involved due to the poor complacence, drug interaction and when preventive measures not prescribed followed by 58 $(26.85 \%)$.

Not preventable when the observed ADRs are not involved in either probably preventable or definitely preventable is included and 48 (22.22\%) Definitely Preventable which includes if any previous reactions or history of allergy to 
the drug and the given drug is inappropriate to the patient clinical condition. (Figure 3).

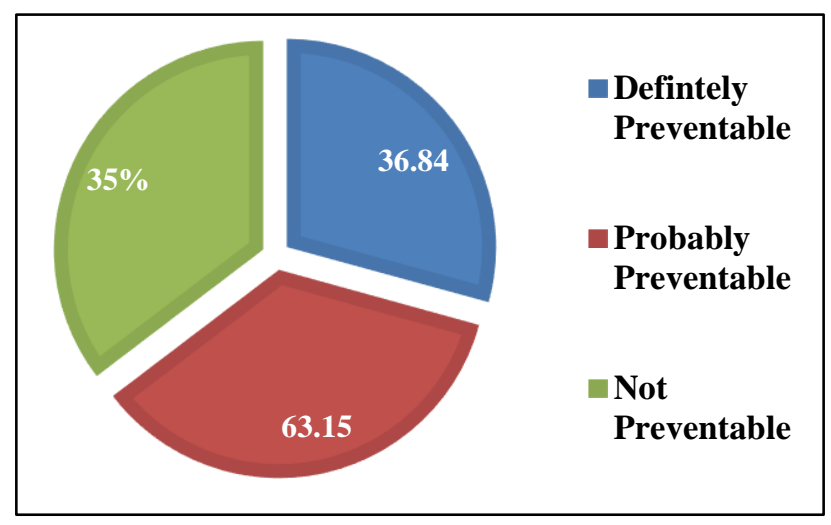

Figure 3: Preventability assessment using modified Schumock and Thornton Scale.

\section{DISCUSSION}

In this study Adverse Drug Reactions associated with different antiretroviral therapy combinations have been observed.

In this study $21.17 \%$ patients were presented with ADRs. This was much lower than that of $94 \%$ reported by Malangu et al, $71.1 \%$ by Sharma et al and $55.34 \%$ by Kumar A et al, but higher than Jha et al. ${ }^{7-10}$ Majority of the ADRs were reported by TLE regimen $(55.55 \%)$ followed by ZLN regimen $(41.66 \%)$ and $\mathrm{LR}$, TL regimen $(2.77 \%)$. Similar findings were reported by Kumar A et al, were ADRs involving TLE regimen (49.23\%) followed by ZLN regimen $(23.85 \%){ }^{11}$

Females $(64.35 \%)$ were more prone to ADRs compared to males $(35.6 \%)$. Similar findings were reported by Kumar $P$ et al, L Margaret et al, where females higher than males. ${ }^{12,13}$ In contrast Jha A et al, a higher number of ADRs in males $(53.5 \%)$ compared to females $(46.5 \%) .{ }^{10}$

Most of the patients were between the age group between $31-35 y e a r s$ was found to be $45(20.83 \%)$ followed by age group between 41-45years was found to be 40 (18.51\%). In contrast Kumar $\mathrm{R}$ et al, reported that most of the patients were between the age group of 18-30years (44.73\%) followed by $31-40 y e a r s(28.7 \%) .{ }^{14}$ These variations may be due to sample size, study design, demographic variations, hormonal effects, drug metabolism and elimination. ${ }^{15}$

Present study reported majority of ADRs were observed in central nervous system $(59 \%)$ followed by metabolic disorder (57\%), haematological system (50\%), gastrointestinal system (28\%) and dermatological system (20\%). Likewise, Kumar R et al, results disclosed that gastrointestinal system was found to be (28.91\%) and Dermatological study (11.83\%) adverse drug reactions which were close to present study. ${ }^{14}$
The collected ADRs were assessed for causality by WHOUMC scale which revealed $78.7 \%$ of ADRs were possible followed by $14.35 \%$ probable and $6.94 \%$ were certain. ${ }^{15}$ Similar results were showed by Oumar A et al, study revealed $(53.9 \%)$ probable, $(46.1 \%)$ possible. ${ }^{16}$ In contrast Anwikar et al, study showed (96.49\%) possible, (3.5\%) probable. $^{17}$

In present study, severity assessment has been done by modified Hartwig and Siegel's scale, where most of the ADRs were mild $(64.42 \%)$ followed by moderate $(26.85 \%)$ and severe $(9.72 \%){ }^{18}$ Similar results were showed by Kumar R et al. ${ }^{14}$ In contrast Kumar A et al, study showed $(77.19 \%)$ moderate followed by (14.2\%) severe and $(8.77 \%)$ mild. $^{11}$ Decrease immunological status and multiple drug intakes were the two important factors associated with severity of drug reacitons. ${ }^{16}$

In present study preventability assessment has been done using Schumock and Thornton scale, (50.92\%) probably preventable, (26.85\%) not preventable and $(22.22 \%)$ definitely preventable. ${ }^{19}$ Similar results were found to be in Kumar P et al, study. ${ }^{11}$ In contrast Bhuvana et al, study showed $(30 \%)$ preventable and $(70 \%)$ not preventable. ${ }^{20}$ Majority of the ADRs in present study were preventable as the doses of the drugs were within the therapeutic range and in accordance with immunological condition of the patient.

Limitations of this study were the study was conducted for a short period at a single center and with a small sample size thus the data cannot be representative of national statistics.

Being an outpatient department-based study, it is quite possible that some ADRs were missed that were transient or too mild to have inconvenienced the patient to report.

\section{CONCLUSION}

The prevalence of ADRs due to ART regimen is common, most of the ADRs were observed in patients receiving TLE regimen. So, patients receiving TLE regimen need intensive monitoring to early detect and prevent the ADRs. The management of HIV is increasingly complex, due to ADRs and risk of drug resistance. Doctors, nurses, pharmacist must focus on early detection and prevention of ADRs, based on their severity (self-limiting and potentially serious).

\section{ACKNOWLEDGEMENTS}

Authors would like to thank to all the physicians and PGs of Anti-retroviral therapy centre, SVRRGG hospital for allowing us to perform the present work and also for their support and cooperation.

Funding: No funding sources

Conflict of interest: None declared 
Ethical approval: The study was approved by the Institutional Ethics Committee

\section{REFERENCES}

1. Srikanth BA, Babu SC, Yadav HN, Jain SK. Incidence of adverse drug reactions in human immune deficiency virus-positive patients using highly active antiretroviral therapy. J Advanced Pharmaceut Technol Res. 2012 Jan;3(1):62-7.

2. Masenyetse LJ, Manda SO, Mwambi HG. An assessment of adverse drug reactions among HIV positive patients receiving antiretroviral treatment in South Africa. AIDS Res Therapy. 2015 Dec;12(1):6.

3. Joint United Nations Programme on HIV/AIDS (UNAIDS). Global report: UNAIDS report on the global AIDS epidemic 2018. Available at: http://www.unaids.org/en/resources/fact-sheet.

4. Crabtree-Ramírez B, Villasís-Keever A, GalindoFraga A, del Río C, Sierra-Madero J. Effectiveness of highly active antiretroviral therapy (HAART) among HIV-infected patients in Mexico. AIDS Res Human Retroviruses. 2010 Apr 1;26(4):373-8.

5. Languluri Reddenna, Shaik Ayub Basha, Donthu Venu Gopal, Tedlla Rama Krishna. Highly Active Antiretroviral Therapy: Incidence of Adverse Drug Reactions. Int $\mathrm{J}$ Allied Med Sci Clin Res. 2013:1(1):25-30.

6. Mulatu WN, Worku A. Assessment of knowledge, attitude and practice of health professionals towards adverse drug reaction reporting and factors associated with reporting. J Pharmacovigilance. 2014 Jun 27.

7. Malangu NG. Self-reported adverse effects as barriers to adherence to antiretroviral therapy in HIV-infected patients in Pretoria. South African Family Practice. 2008 Sep 1;50(5):49.

8. Sharma A, Vora R, Modi M, Sharma A, Marfatia Y. Adverse effects of antiretroviral treatment. Indian $\mathrm{J}$ Dermatol Venereol Leprol. 2008 May 1;74(3):234-7.

9. Kumar A, Majhee L, Gari M. Causality, severity and preventability assessment of adverse drug reactions in patients received anti-retroviral therapy in a tertiary care hospital: a retrospective study. National J Physiol Pharmacy Pharmacol. 2017;7(2):178-82.

10. Jha AK, Gadgade A, Shenoy AK, Chowta MN, Ramapuram JT. Evaluation of adverse drug reactions in HIV positive patients in a tertiary care hospital. Perspectives Clin Res. 2015 Jan;6(1):34-8.

11. Patil PT, Pawar MP, Halasawadekar NR, Shinde MP, Kumbhar AV, Rathod MS. Current pattern of adverse drug reactions to anti-retroviral therapy in an antiretroviral therapy centre attached to a government medical college of Maharashtra, India: a retrospective study. Int J Basic Clin Pharmacol. 2018 Jan 20;5(6):2438-43.

12. Margaret L, Quashie AA, Essel A, Ernest K, Ganu V, Neequaye A. Adverse drug reactions to antiretroviral therapy during the early art period at a tertiary hospital in Ghana. Pan Afri Med J. 2014;18:25.1-6.

13. Kumar P, Prasad SR, Parthasarathi G, Krishna U. Assessment of adverse drug reactions to antiretroviral agents among HIV patients. J Applied Pharmaceut Sci. 2018;8(2):79-82

14. Kumari R, Satish C, Manju G, Abha K. An assessment of adverse drug reaction patterns among HIV positive patients receiving antiretroviral therapy in a tertiary care hospital. Int J Pharmacol Res. 2017;7(04):88-93.

15. Zaki S. Adverse drug reaction and causality assessment scales. Lung India. 2011 Apr 1;28(2):152.

16. Oumar AA, Diallo K, Dembélé JP, Samaké L, Sidibé $\mathrm{I}$, Togo $\mathrm{B}$, et al. Adverse drug reactions to antiretroviral therapy: prospective study in children in sikasso (mali). J Pediatr Pharmacol Therapeutics. 2012 Dec;17(4):382-8

17. Anwikar SR, Bandekar MS, Smrati B, Pazare AP, Tatke PA, Kshirsagar NA. HAART induced adverse drug reactions: a retrospective analysis at a tertiary referral health care center in India. Int J Risk Safety Med. 2011 Jan 1;23(3):163-9.

18. Hartwig SC, Siegel J, Schneider PJ. Preventability and severity assessment in reporting adverse drug reactions. Am J Health-System Pharmacy. 1992 Sep 1;49(9):2229-32

19. Singh S, Singh PK. Pattern and impact of drugs targeted toward toxicity amelioration in patients receiving cancer chemotherapy. Perspectives Clin Res. 2018 Jan;9(1):23.

20. Bhuvana KB, Hema NG. A prospective observational study of adverse drug reactions to antiretroviral therapy: type and risk factors in a tertiary care teaching hospital. Int J Basic Clin Pharmacol. 2017 Jan $2 ; 3(2): 380-4$.

Cite this article as: Reddy MT, Prasad DTS, Reddy SG, Dudu S, Rameela M, Punnamaraju KP, et al. A pharmacovigilance study of antiretroviral therapy in HIV positive out patients at a tertiary care teaching hospital. Int J Basic Clin Pharmacol 2018;7:2419-23. 